\title{
INTRAOCULAR FOREIGN BODY OF FORTY-SIX YEARS' DUR-
}

\section{ATION.}

Walter Scott Franklin, M.D., F.A.C.S., and Frederick C. Cordes, M.D.

\author{
SAN FRANCISCO, CALIFORNIA.
}

The case here reported showed remarkable tolerance of copper within the cye, but there was ossification and sympathetic irritation of the fellow eye requiring entucleation. Contributed from the Department of Oplithalmology, ['niversity of California Medical Sichool.

In reporting this case, we fecl that the duration of forty-six years is of sufficient interest to warrant its presentation. A consideration of intraocular foreign bodies, especially of copper, is included.

The literature is replete with case reports of foreign bodies which at varying intervals have caused the removal of the eye thru late inflammatory reaction. Quoting de Schweinitz" "Foreign bodies may be tolerated for long periods of time-but can never be trusted."

Mr. F. C. B., age 58, reported to us from Oroville, California, on January 12,1922 , complaining of an inflamed, swollen left eye which was extremely painful. He gave the following history:

At the age of 12 , while hitting a percussion cap with a hammer, it exploded and struck him in the left eye. The eye was badly inflamed for a number of weeks and has been blind since the accident. Does not know if foreign body is present, as he has not had an $\mathrm{X}$-ray examination. The eyeball was quiescent until four months ago when it flared up for a short time. During this period the good eye was sensitive to light. Since then, at varying intervals, the injured eye has become slightly inflamed. The last two weeks, and especially the last few days, the condition has become more marked and, in addition, has become progressively painful, so that patient was unable to sleep. For the past two days, the right eye has been troublesome, being sensitive to light.

Examination: R. V. 8, with correction 1.0. L. Amaurotic.

R.: Pupil contracted, reacts slowly to light, otherwise external examination negative. Fundus negative. L.: Marked edema of both licls with ble- pharospasin and excessive lacrimation; extreme ciliary injection. Cornea edematous with whitish concretions and a leucoma adherens. Anterior chamber abolished. No light reflex. Tension ++ . X-ray examination showed an intraocular foreign body, together with ossification. The diagnosis was iridocyclitis of the left eye due to retained intraocular foreign body, together with sympathetic irritation of the right. Immediate enucleation was insisted upon.

At operation the edema of the lids was so marked that the lid speculum was introduced with difficulty. The conjunctiva, Tenon's capsule and the underlying muscles were all adherent, and the muscles were isolated with difficulty. Recovery was uneventful, the symptoms of the right eye subsiding almost immediately.

Sectioning the eye revealed a practically complete bony cup from the ora serrata to the optic disc which, microscopically, showed true ossification. There were marked degenerative changes in the vitreous. The foreign body consisted of a thin irregular piece of copper $3 \mathrm{~mm}$. square.

The case brings up several points of interest: First, the necessity of careful exclusion of a foreign body in all ocular injuries; second, the tolerance of the different structures of the eye to foreign bodies; third, the diversity of tolerance of the globe toward various substances, especially copper; fourth, the prognosis in retained intraocular foreign bodies.

In our case, apparently no attempt was made to ascertain the presence or absence of an intraocular foreign body at the time of injury. Jackson ${ }^{2}$ places particular emphasis on the necessity of determining this point. A case presented by $H$. Barkan ${ }^{3}$ was that of a 
machinist who, two years previously, had an apparently sujerficial injury to the eye, yet when seen by Barkan, there was a definite siderosis and the $\mathrm{X}$-ray examination demonstrated an intraocular foreign body. The literature presents many similar cases. In all eye injuries in which there is even the remotest possibility of an intracular foreign body, an X-ray examination is imperative.

The tolerance of the different structures of the eye to foreign bodies varies greatly, the anterior chamber at times being very resistant. Meller ${ }^{4}$ re-

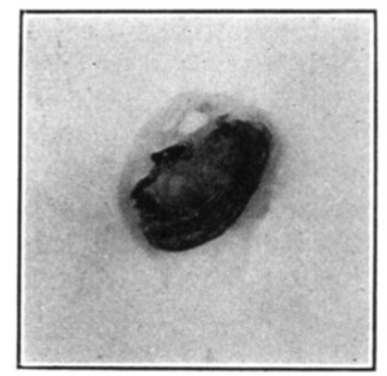

Fig. 1.-X-ray photograpit of half of glolse showing ossification and foreign body.

ports a sliver of iron in the anterior chamber of twenty-six years' duration without reaction.

Foreign bodies of the iris usually set up a marked inflammation. The progynosis, as a rule, is good because of the ease of removal; in the difficult cases an iridectomy usually suffices. Bruner's case retained a piece of steel in the iris for ten years before an inflammatory process necessitated its removal by iridectomy. Duane ${ }^{6}$ reported a similar case, while that of Reitsch ${ }^{\top}$ tolerated a sliver of iron in the anterior chamber and iris for twenty-seven years and then, because of an iridocyclitis, required surgical intervention. The case report of Ollendorff ${ }^{8}$ tells of an iron splinter that was quiescent in an iris for thirty years, and that of Birnbacher $^{9}$ twenty-five years, while the longest period of tolerance to a foreign body, to our knowledge, is that of a fragment of stone remaining in the iris for fifty-four years, as reported by Dickey. ${ }^{10}$
The lens is among the most resistant structures of the eye to the presence of foreign bodies. Würdemann, ${ }^{11}$ in his book, states that a foreign body in the lens is less likely to produce injurious symptoms or sympathetic inflammation than in other parts. Knapp, ${ }^{12}$ in one of his cases, however, had a panophthalmitis following the removal of a lenticular foreign body within a few hours after injury. Lewis' calse ${ }^{13}$ retained a splinter of iron in the

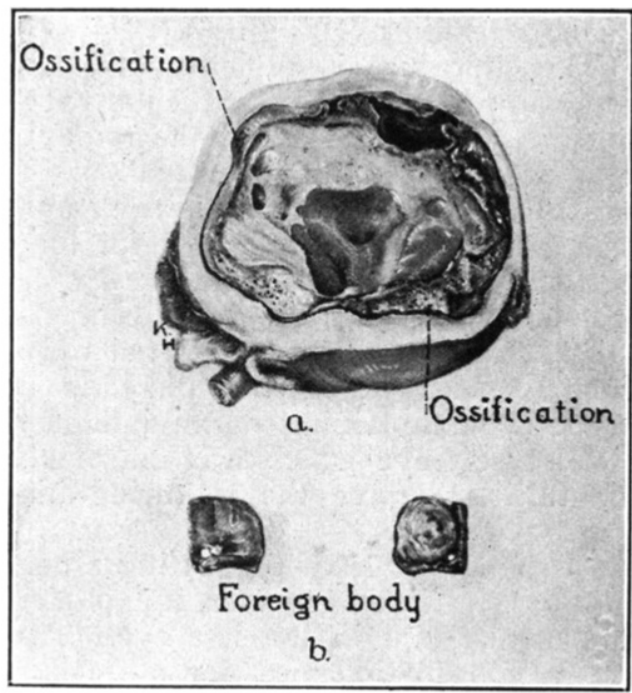

Fig. 2. (A) Section of globe showing degree of ossification. (B) Foreign body.

lens without symptoms for six years, while Doyne's ${ }^{14}$ case was quiescent for thirty years, and that of Nottage ${ }^{15}$ thirty-two years. Doyle ${ }^{16}$ reports a case of thirty-five years' standing, and in Blaxland's ${ }^{17}$ case a lenticular foreign body was tolerated for forty years. In Sattler's ${ }^{18}$ experience, all particles of iron in the lens produced a cataract. This statement is also upheld by Elschnig $^{19}$ who advises lance incision and extraction in these cases.

Of foreign bodies in the vitreous, Fuchs ${ }^{20}$ states that these usually excite violent inflammation from which the eye is destroyed. In exceptional cases a forcign body is tolerated so that it may be seen for years. Würdemann ${ }^{11}$ comments that in the posterior segment they usually destroy sight. cause 
atrophy of the globe and may result in sympathetic ophthalmia. The literature records the varying intervals of toleration in different cases. That of Reese $^{21}$ required attention after five years, while in Meissner's:- there was a spontaneous expulsion after six years. Schonberg's: case remained
Clearly by Leber ${ }^{29}$ in his classical work. The details are too well known to necessitate repetition, but a few facts bear emphasis. He found that copper is among the most irritating of foreign bodies and that its action is a chemical one due to oxidation. Lead is the least dangerous of the metals. Boehm ${ }^{39}$

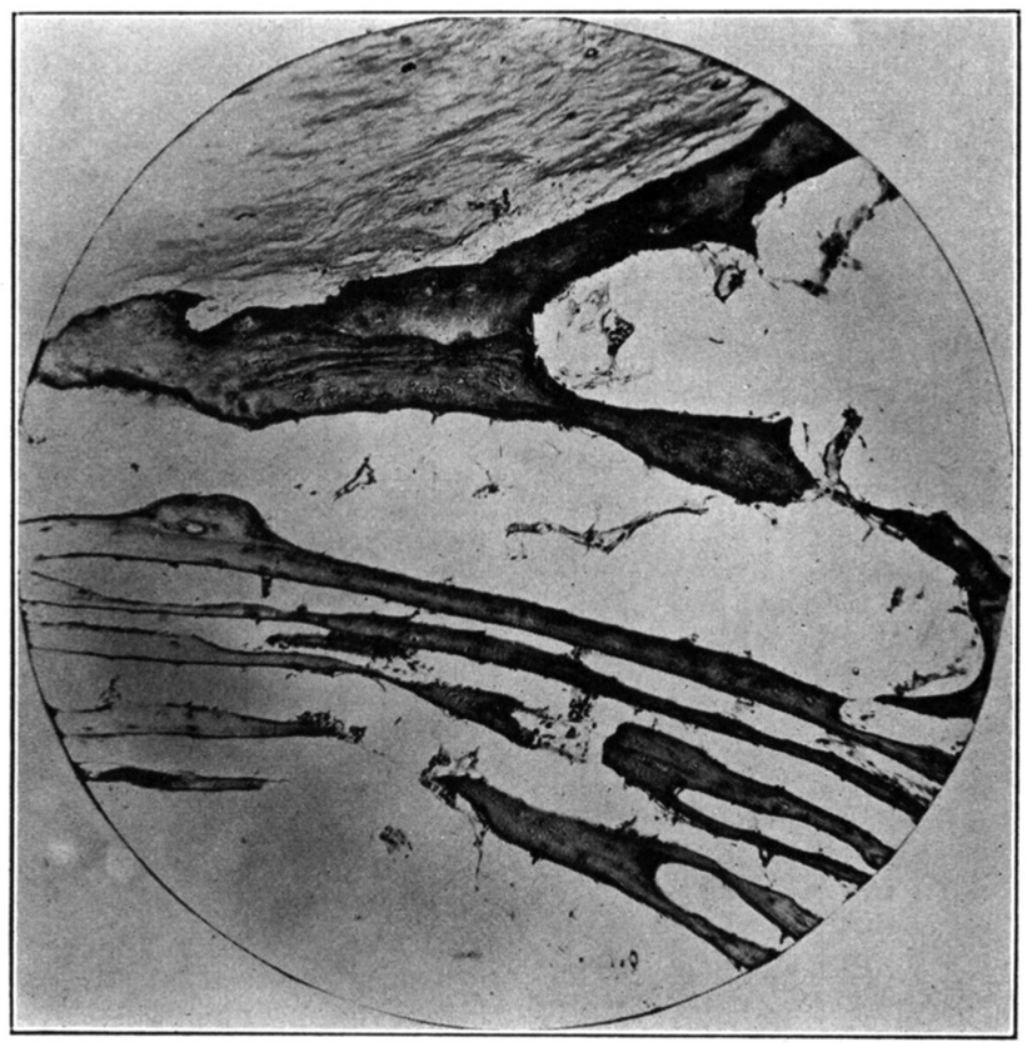

Fig. 3.-Microphotograph thru sclera and bone formation.

quiescent for twelve years, Fugita's ${ }^{24}$ fourteen, while Dickey $\$^{25}$ required interference after seventeen years. Roll ${ }^{20}$ reports a case of eighteen years' duration, Banister" years' and Jackson" one of twenty-one years' which required no attention and had useful vision. Buckley's ${ }^{28}$ case tolerated a foreign body in the posterior segment for twenty-nine years before enucleation became necessary. Our case, after a period of forty-six years, required surgical interference

The tolerance of the ocular structures to the various types of foreign bodies varies markedly, as is shown concludes that fragments of lead behave more favorably toward the tissues than other metals. The prognosis is good even as concerns sympathetic ophthalmia. Wirtz ${ }^{31}$ also substantiates this and adds that copper is among the most dangerous. Rollet and Aurand, ${ }^{32}$ in their experiments, found that aluminum caused no reaction. Löwenstein, ${ }^{33}$ in an interesting report, advises conservative treatment of fragments of stone as they are well borne. During the late war, Hertel ${ }^{34}$ reported 242 cases of intraocular foreign bodies, giving the reason for the failure of the magnet in many cases as being due to 
the alloys which were employed. These alloys, in addition, hastened siderosis. In a number of cases where it was impossible to remove all the foreign bodies, the eyes tolerated them surprisingly well. With copper fifty percent of the eyes were lost.

Leber" $^{29}$ says of copper: "In as far as we know at present, metallic copper is the commonest chemical substance which produces suppuration in the eye; the retention of a fragment of which occurs not infrequently, especially from the explosion of percussion caps." Van Lint $^{35}$ concludes that bits of copper are, of all foreign bodies, most dangerous to the globe. Their destructive action is much more rapid and far reaching than iron, Lehmann ${ }^{35}$ formulates his conclusions regarding slivers of copper in the vitreous as follows: Copper in the vitreous chamber is a serious danger for vision; immediate extraction to preserve the vision is indicated in every case, even if there be great difficulties. It is interesting to note that here the commonest causes of intraocular copper as described by Hirschberg ${ }^{37}$ in 1895 still applies. His classification is: First, discharge of poorly constructed guns for children; second, biting of or accidental explosion of percussion caps; third, in industrial workers. He also comments that intraocular copper is a constant menace to an eye.

An explanation as to the formation of bone with foreign bodies is given by E. Treacher Collins, ${ }^{38}$ who states that in one of his cases the probable cause of this condition is that the trauma and the entrance of the foreign body had caused a partial rupture of the choroid and bone developed in the plastic exudate thrown out.

According to Fuchs, ${ }^{39}$ if there is a foreign body in the eyc which cannot be removed at once, the eye is almost always lost. Also, in stating the prognosis the danger which threatens the other eye because of sympathetic inflammation must not be forgotten. After an unsuccessful attempt to remove a foreign body, that eye must be considered a constant source of danger to its fellow. This applies particularly when the foreign body is located in the posterior chamber, and especially if it is copper. If the patient's intellect is such that the risk can be understood and an oculist is accessible, such an eye, if quiescent, can be left in situ. If this is not the case, enucleation should be resorted to, particularly if the vision has been injured.

In conclusion, there are several points which bear emphasis.

1. An eye injury which has even the remotest possibility of an intraocular foreign body demands an X-ray examination.

2. The tolerance of the various structures of the eye to foreign bodies varies greatly. In one case a bit of stone was tolerated in the iris for fiftyfour years, and in our case a piece of copper in the posterior chamber for forty-six years, while the removal of a piece of steel from a lens a few hours after injury, in another case produced a panophthalmitis.

3. The reaction of the eye to various foreign substances differs vastly, lead, aluminum and stone causing the least reaction, while copper ranks among those causing the most marked.

4. The prognosis of a retained foreign body should always be guarded and, in the case of copper, the eye should be enucleated unless the patient can be kept under proper supervision.

\section{BIBIIOGRAPHY.}

1. De Schweinitz. Diseases of the Eye, 9 th Ed., p. 319.

2. Jackson, E. N. Y. Med. Journ., 1899, lxx, 449.

3. H. Barkan. Case presented to Eye Sec., S.F. County Med. Soc.

4. Meller, J. Ophth. Gesell in Wien., Dec., 1913, Cent. f. p. Augenh., v. 38, p. 17.

5. Bruner. Ophthalmology, Oct., 1906.

6. Duane. Fuchs' Textbook of Öphthalmology, 2nd Fd., p. 235

7. Reitsch. Klin. M. f. Augenh., v. 53 p. 545.

8. Ollendorff. Zeit. f. Augenh., v. 43, p. 571.

9. Birnbacher, A. Cent. f. prakt. Augenh., 1885, ix, 228. 
10. Dickey, J. West Virginia Med. J.. Sept. 1909.

11. Würdemann. Injuries to the Eye, p. 363.

12. Knapp, H. Arch. Ophth., Jan., 1906.

13. Lewis, F. P. Arch. Ophth., Jan., 1906.

14. Doyne. Trans. Ophth. Soc. U. K., v. xiv.

15. Nottage. Ophth. Rec. viii, p. 78.

16. Doyle. J. Ophth., Otol. and Laryngol., 1895, vii, p. 304.

17. Blaxland, F. Med. Journ., Australia, June 5, 1920, p. 542.

18. Sattler. Internat. Cong. Ophth., Utrecht, 1906, p. 433.

19. Elschnig. Münch. med. Woch., No. 15, 1910.

20. Fuchs. Textbook Ophth., 2nd Ed., p. 433.

21. Reese. Arch. of Ophth,, v. 44, p. 93.

22. Meissner. Woch. f. Therap. v. Hyg. d. Auges., v. 22, p. 49.

23. Schönberg, M. Arch. of Ophth., v. 44, pp. 72-196.

24. Fugita, $H$. Archiv f. Augenh., v. 75 , p. 99.

25. Dickey. West Virginia Med. J., July, 1908.

26. Roll. A. J. O., v. 4, 1921, p. 367.

27. Banister. Ann. Ophth. and Otol., 1895, iv, p. 353.

28. Buckley, J. A. J. O., v. 2, 1919, p. 746.

29. Leber, T. Trans. Ophth. Soc. of U. K., xii, 1892, p. 4.

30. Boehm. Klin. M. f. Augenh., July-Aug., 1916.

31. Wirtz, R. Wchnsch. f. Therap. u. Hyg. d. Auges., Feb. 16, 1905.

32. Rollet and Aurand. Rev. Gén. d'Opht., v. 32, p. 693.

33. Löwenstein, A. Arch. of Ophth., v. 47, p. 112.

34. Hertel, E. Ann. d'Ocul., v. 154, p. 165.

35. Van Lint. Clin. Opht., v. 19, 565 .

36. Lehmann, A. Klin. M. f. Augenh., v. 52, p. 915.

37. Hirschberg, J. Duet. med. Wchnsch., xx, p. 313.

38. E. Treacher Collins. Ophth. Review, 1892. xl, 135.

39. Fuchs. Textbook of Ophth., 2nd Ed., p. 235.

\title{
TECHNIC OF OBSERVATION: WITH THE GULLSTRAND SLIT LAMP
}

\author{
Robert Von Der Heydt, M.D.
}

CHICAGO, ILIINOIS.

To make microscopy of the living eye with the slit lamp a practical clinical method, requires thoro familiarity with the manner of doing it. This paper furnishes a guide to the practice necessary to master it.

The use of intense focal illumination in conjunction with observation of the living human eye under binocular magnification, as a method of refinement in diagnosis has made such advancement within the last few years, that a short outline of the technic of its application may be of aid to the many new workers in this interesting field of ophthalmologic research.

The fear that this method, owing to its supposed complexity, would of necessity have to confine itself to clinical application, and not be available to routine office practice, has been proven unfounded. To prove this it may be stated that a patient can be seated, the apparatus adjusted, the cornea, iris, lens, and anterior vitreous of both eyes carefully examined, with- in a period of six minutes. This, however, does not allow for a stoppage in contemplation of the many astounding and amazing new findings observable, even in normal eyes.

Of first importance is the seating of the patient in a comfortable position with his chin placed in a chin rest and forchead firmly fixed against the pad. This is self evidently as essential as is the fixed clamping of a slide on the table of a microscope. For all ordinary purposes it is only necessary for the patient to be asked to fix his gaze onto the observer's forehead as it appears above the microscope. The illumination is from the temporal side, while observation, except for certain special purposes, is in the direction of the antero-posterior axis of the eye. The 